International Journal of Research in Engineering and Innovation
(IJREI)

\title{
Thermodynamic analysis of vapor compression refrigeration cycle using expander as an expansion device
}

\author{
R.S. Mishra, Shyam Agarwal
}

Department of Mechanical, Production, Industrial and Automobiles Engineering, Delhi technological University, Delhi, India

\begin{abstract}
In the current paper, the thermodynamic analysis of vapor compression refrigeration cycle using expander as an expansion device has been carried out. It consists two vapor compression refrigeration cycle one is the main and other is subcooler cycle. The main cycle consists of a subcooler (evaporator of the subcooler cycle) and an expander in place of throttle valve. The compressor of the subcooler cycle is coupled to the expander of main cycle such that the expander work is equal to the compressor work of subcooler cycle. The evaporator of subcooler cycle is the subcooler for main cycle which provides subcooling to the refrigerant of main cycle. The HFC R134a and HFOs R1234yf and R1234ze have been considered in the present analysis. An EES (Engineering Equation Solver) based program has been developed to compute the performance parameters i.e. COP and exergy efficiency. The effect of degree of subcooling and evaporator temperature of main cycle on COP and exergy efficiency have been observed. The results show that the $\mathrm{COP}$ and exergy efficiency increase with increase in degree of subcooling and COP enhances up to $38.75 \%$ for degree of subcooling of $5^{\circ} \mathrm{C}$. The COP also boost up with increase in evaporator temperature. The refrigerant R1234ze is better than that of R1234yf.

(C) 2019 ijrei.com. All rights reserved

Keywords: Subcooling, Expander, Vapor Compression Refrigeration, Exergy-Energy Analysis, Irreversibility Analysis
\end{abstract}

\section{Introduction}

Energy and exergy efficiencies are the major issues now a day. The energy efficient systems are in current demand particularly refrigeration efficient systems.

The energy and exergy of the system can be enhanced using subcooling method to the conventional vapor compression refrigeration cycle. She et al.[1] proposed subcooling method for vapor compression refrigeration cycle using expansion power recovery. Mota-Babiloni et al. [2] reviewed the recent developments in commercial refrigeration and focused on system modifications (as dedicated subcooling or the implementation of ejectors), trigeneration technologies (electrical, heating and cooling demand) and better evaporation conditions control. They concluded that the hydrocarbon, $\mathrm{HFO}$ and $\mathrm{CO}_{2}$ are HFC replacements. Park et al. [3] reviewed recent studies on advanced vapor compression cycle technologies. These technologies are categorized in three groups: subcooling cycles, expansion loss recovery cycles, and multi-stage cycles. The subcooling cycle research is focused on a suction-line heat exchanger, thermoelectric subcooler and mechanical subcooler. The expansion loss recovery cycles are mainly focused on utilizing an expander and ejector. Llpois et al. [4] reviewed $\mathrm{CO}_{2}$ subcooling method to upgrade the performance of $\mathrm{CO}_{2}$ refrigeration plant in the recent years, with overall improvements up to $12 \%$ with internal heat exchangers, $22 \%$ with economizers, $25.6 \%$ with thermoelectric systems and $30.3 \%$ with dedicated subcooling methods. Arora and Kaushik [5] performed theoretical analysis of an actual vapour compression refrigeration (VCR) cycle for exergy analysis. They concluded that the efficiency defect was highest in the condenser while lowest in the liquid vapour heat exchanger. Meng et al. [6] measured the viscosity of 2,3,3,3-tetrafluoroprop-1-ene (R1234yf) and trans1,3,3,3-tetrafluoropropene (R1234ze(E)) in the temperature of (243 to 363 ) $\mathrm{K}$ from saturated pressures up to $30 \mathrm{MPa}$ using a vibrating-wire viscometer and reported that the both the refrigerants are promising.Qiu et al. [7] performed 128 and 131 experiments for R1234yf and R1234ze to measure the density of these refrigerants and proposed to replace R134a with R1234yf and R1234ze in automobile air-conditioning. 


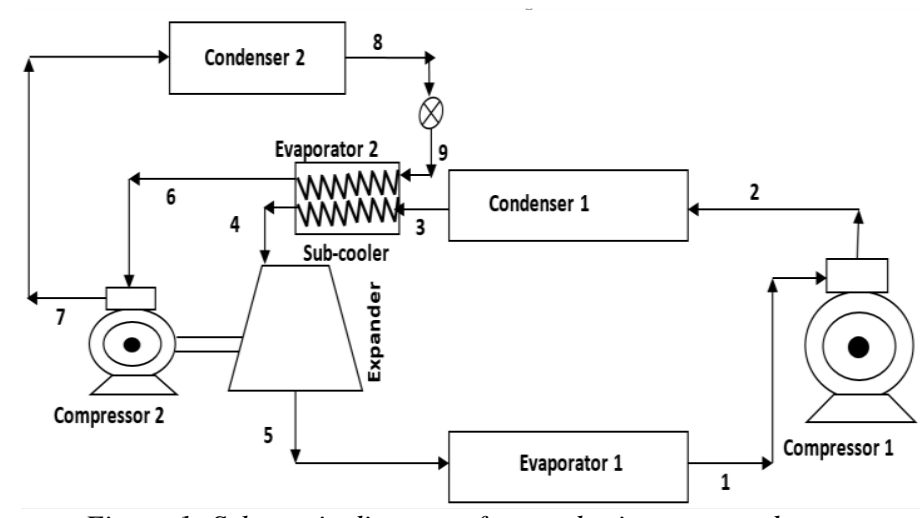

Figure 1: Schematic diagram of expander incorporated vapor compression refrigeration cycle

Agrawal S. (2019) also carried out thermodynamic and exergy analysis of various thermal systems and found that when evaporator temperature is increasing first law efficiency in terms of COP is increasing and exergy efficiency is decreasing and condenser temperature is increasing first law efficiency in terms of COP is decreasing and exergy efficiency is decreasing Similarly exergy destruction ratio (EDR) of system is also increasing with increasing evaporator and condenser temperatures.

\section{Description \& Modeling of System}

\subsection{Description of system}

Figure 1 shows the schematic diagram of expander incorporated vapor compression refrigeration cycle in which the expander is taking the place of expansion vale or throttle valve. It consists of two vapor compression refrigeration cycles. The main vapor compression refrigeration cycle is in lower evaporator temperature circuit and the other vapor compression refrigeration cycle designated as subcooler cycle is in higher evaporator temperature circuit. The two refrigeration cycles are coupled to each other by a subcooler. The subcooler is the evaporator of the subcooler cycle. The refrigerants considered in the cycles are R134a, R1234yf and R1234ze. The main VCR cycle and the subcooler cycle are having same refrigerant at a time during the operation.

The main VCR cycle consists of an evaporator, a compressor, a condenser and an expander and the subcooler cycle consists of a compressor, a condenser, and expansion valve and an evaporator designated as subcooler. The expander of main VCR cycle is coupled to the compressor of sub-cooler VCR cycle through a shaft such that the compressor work of subcooler VCR cycle is equal to the expander work of main VCR cycle. The network input of the subcooler VCR cycle is provided by the expander work output of main VCR cycle. The subcooler sub-cools the liquid refrigerant leaving the condenser 1 of the main VCR cycle. The subcooler couples the two cycles such that the heat rejected by the liquid condensate of the main VCR cycle is absorbed by the vapor refrigerant of the subcooler VCR cycle. No external heat rejection is considered in the subcooler.
The refrigerant vapor leaving the evaporator 1 of the main VCR cycle enters into the compressor 1 at state point 1 . The high pressure high temperature refrigerant vaporenters into the condenser 1 at state point 2 after compression. The vapor refrigerant changes into the liquid refrigerant in the condenser 1. The condensate vapor of the main cycle leaving the condenser 1 and enters into the subcooler at state point 3 . The condensate vapor of the main VCR cycle is subcooled by the subcooler which increase the net refrigeration effect of the main VCR cycle.

The evaporator 2 of the subcooler cycle is also a subcooler. The liquid-vapor refrigerant receives heat from the liquid condensate of the main VCR cycle in the subcooler from state 9 to 6 . The refrigerant vapor is compressed by the compressor 2 from state 6 to 7 . The high pressure and high temperature refrigerant vapor is condensed by the condenser 2 from state 7 to 8 .

The liquid refrigerant leaving the condenser 2 is expanded by expansion valve from state 8 to 9 . Finally, the refrigerant vapor after expansion enters into the subcooler.

In this way, the use of expander and a subcooler enhances the COP of the main VCR cycle.

\subsection{Thermodynamic modeling}

Thermodynamic analysis of expander incorporated vapor compression refrigeration cycle has been carried out in the current presentation. Steady state governing equations have been formed on the basis of first and second law of thermodynamics. Energy, work and mass balances have been carried out for each component of the system. An EES (Energy Equation Solver) software bases program has been developed to solve the governing equation used in the analysis. The COP of the expander incorporated vapor compression refrigeration cycle is given by the equation (1).

$$
\mathrm{COP}=\frac{\dot{\mathrm{Q}}_{\mathrm{e}}}{\dot{\mathrm{W}}_{\mathrm{comp} 1}}
$$

Where $\dot{Q}_{\mathrm{e}}$ is the net refrigeration load of the evaporator 1 in $\mathrm{kJ} / \mathrm{s}$ and $\dot{W}_{\text {comp } 1}$ is the net compressor work of compressor $1 \mathrm{in} \mathrm{kJ} / \mathrm{s}$. The exergetic efficiency of the expander incorporated vapor compression refrigeration cycle is given by the equation (2).

$$
\eta_{\mathrm{ex}}=\operatorname{COP} \times\left|\left(1-\frac{\mathrm{T}_{0}}{\mathrm{~T}_{\mathrm{e} 1}}\right)\right|
$$

Where $T_{0}$ is the ambient temperature and $T_{e 1}$ is the temperature of evaporator 1 in $\mathrm{K}$.

The net-work output of the expander is equal to the net-work output of compressor 2 and is given by equation (3).

$\dot{\mathrm{W}}_{\text {Exp. }}=\dot{\mathrm{W}}_{\text {comp2 }}$

The energy balance in the subcooler (evaporator 2) is given by equation (4).

$\dot{m}_{r, m}\left(\mathrm{~h}_{3}-\mathrm{h}_{4}\right)=\dot{m}_{r, s c}\left(\mathrm{~h}_{6}-\mathrm{h}_{2}\right)$ 
Where $\dot{m}_{r, m}$ and $\dot{m}_{r, s c}$ are the mass flow rate of refrigerant flowing in main and subcooler vapor refrigeration cycle in $\mathrm{kg} / \mathrm{s}$.

\section{Results and Discussion}

The thermodynamic analysis of expander incorporated vapor compression refrigeration cycle has been executed in the current presentation. An EES (Engineering Equation Solver) software based program has been developed for the computation of performance parameters.

The effect of DOS (Degree of subcooling), evaporator1 temperature, and isentropic efficiency of expander 1 and effectiveness of subcooler has been observed on various performance parameters.

\subsection{Effect of degree of subcooling}

The effect of DOS (Degree of subcooling) on COP and exergy efficiency has been shown in Figs. 2, 3 and 4 respectively. Fig. 2 shows the effect of DOS (degree of subcooling) on COP of the expander incorporated vapour compression refrigeration cycle for R134a, R1234ze and R1234yf. The COP of the main VCR cycle increases with increase in DOS. The refrigeration net effect increases due to increase in subcooling for the constant compressor work input.

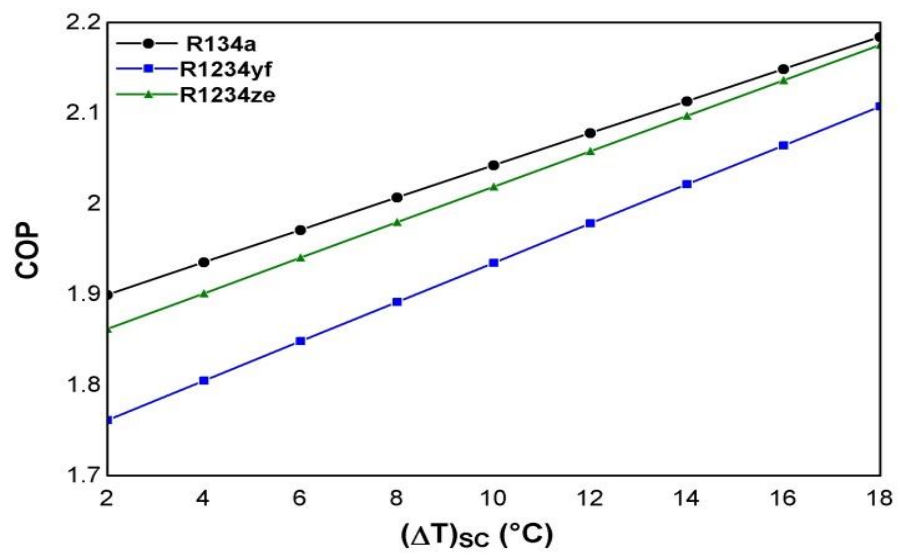

Figure 2: Variation in COP with DOS (Degree of subcooling)

Hence the COP of the main VCR circuit of expander incorporated vapor compression cycle increases with increase in DOS. However the subcooling is due to the subcooler VCR cycle in which the compressor work input is provided by the expander. It is also observed that the maximum and minimum values of COP are 2.184 for R134a and 1.761 for R1234yf

Fig. 3 shows the effect of DOS (Degree of subcooling) on percentage increase in COP of main VCR circuit of expander incorporated vapor compression refrigeration cycle. The percentage increase in COP increases with increase in DOS for considered refrigerants R134a, R1234yf and R1234ze.

The values of COP of the VCR cycle without subcooling are 1.696, 1.519 and 1.64 for R134a, R1234yf and R1234ze respectively. It has been observed that the \% increase in COP is higher for R1234yf than that of R1234ze and R134a. The maximum and minimum \% increase in COP is 38.75 for R1234yf and 11.97 for R134a respectively.

Figure 4 shows the variation in exergy efficiency with degree of subcooling (DOS). The value of exergy efficiency increases with increase in DOS. The exergy efficiency is directly proportional to the COP as given by equation (2) and the COP of the main VCR circuit increase with increase in DOS as shown in Fig. 2. Therefore the exergy efficiency of the main VCR cycle increases with increase in DOS. The maximum and minimum values of exergy efficiency are 0.3397 for R134a and 0.2974 for R1234yf respectively.

\subsection{Effect of evaporator temperature}

The effect of evaporator temperature on COP and exergy efficiency has been shown in Fig. 5and 6 respectively.

Fig. 5 shows the effect of evaporator 1 temperature on COP of the expander incorporated vapor compression refrigeration cycle for considered refrigerants. The COP of the main VCR circuit increases with increase in evaporator 1 temperature. As the evaporator temperature increases the compressor work decreases. Thus, the COP of the main VCR circuit increases with increase in evaporator 1 temperature

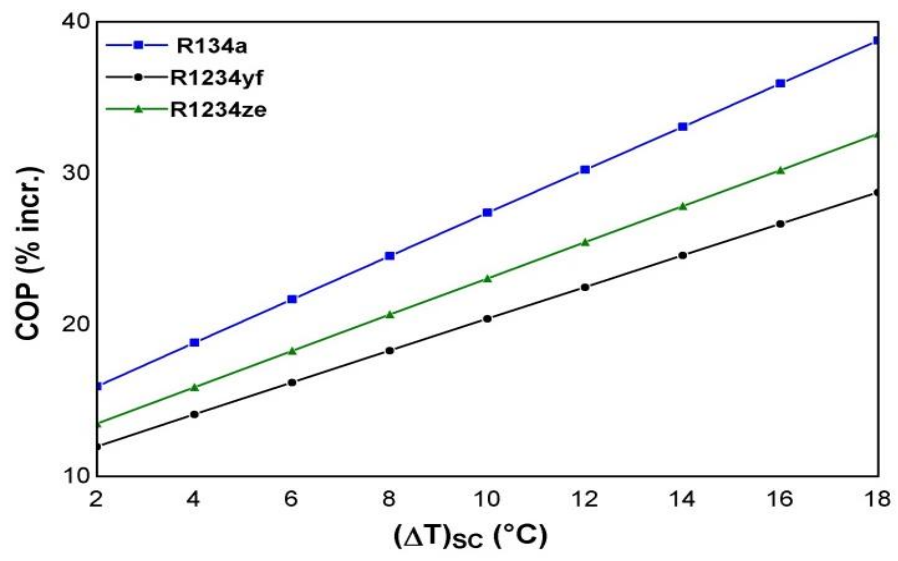

Figure 3: Variation in \% increase in COP with DOS (Degree of subcooling)

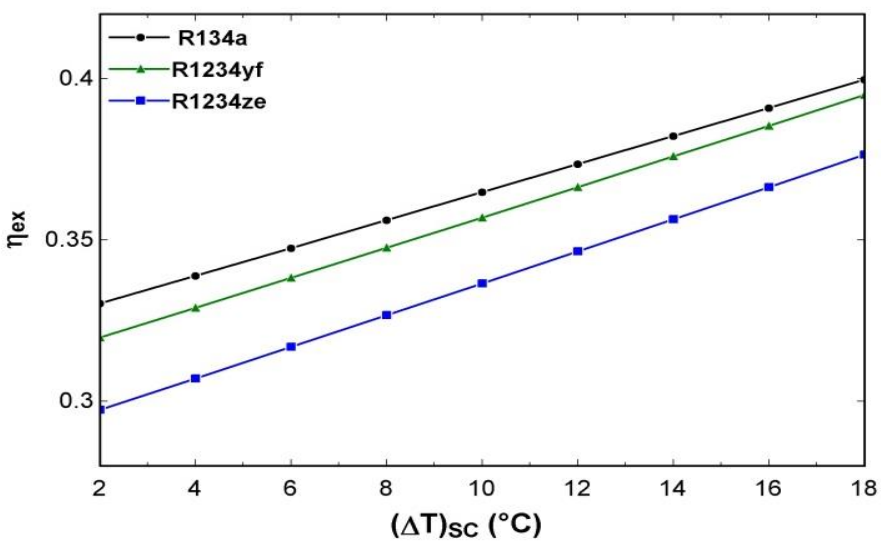

Figure 4: Variation in exergy efficiency with DOS (Degree of subcooling) 


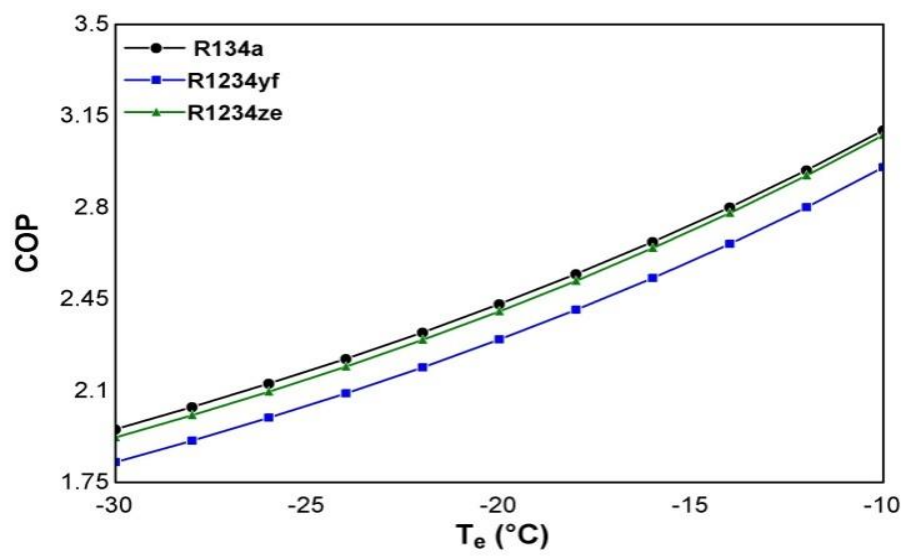

Figure 5: Variation in COP with evaporatorl temperature

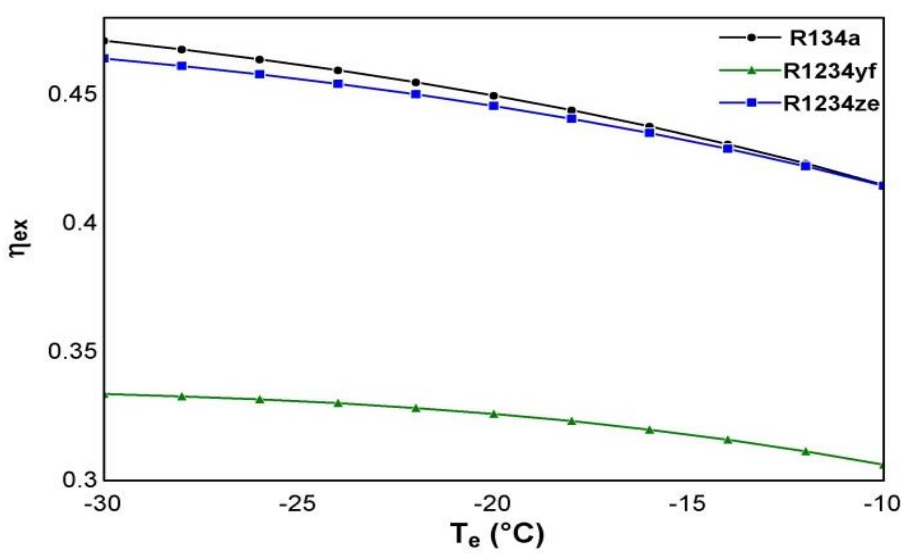

Figure 6: Variation in exergy efficiency with evaporatorl temperature

Fig. 6 shows the effect of evaporator 1 temperature on exergy efficiency of expander incorporated vapor compression refrigeration cycle for considered refrigerants. The value of exergy efficiency decreases with increase in evaporator 1 temperature. As the evaporator 1 temperature increases, the term $\left|\left(1-\frac{T_{0}}{T_{\mathrm{e} 1}}\right)\right|$ decreases as given by eq. (2). However, COP of the cycle increases with increase in evaporator 1 temperature. Thus, the exergy efficiency of the main circuit of expander incorporated VCR cycle.

\section{Conclusions \& Recommendations}

Thermodynamic analysis of expander incorporated vapor compression refrigeration cycle has been carried out in which sub-cooling is provided by the subcooler vapor compression refrigeration cycle to the main vapor compression refrigeration cycle. The refrigerants R134a, R1234yf and R1234ze have been considered for the present analysis. The main conclusions of the analysis are given below:

- The COP and exergy efficiency of the main VCR circuit of the expander incorporated vapor compression refrigeration cycle increases with increase in degree of sub-cooling.

- The COP of main VCR cycle increases with increase in evaporator 1 temperature. However, the exergy efficiency of the cycle decreases with increase in evaporator 1 temperature.

- R1234ze performs better than that of R1234yf.

- The performance of R1234ze is comparable to the R134a.

- The COP of the cycle using expander and sub cooler (both) enhances up to $38.75 \%$ as compared to using without expander

\section{References}

[1] She, X., Yin, Y., \& Zhang, X. (2014). A proposed subcooling method for vapor compression refrigeration cycle based on expansion power recovery. International Journal of Refrigeration, 43, 50-61.

[2] Mota-Babiloni, A., Navarro-Esbri, J., Barragán-Cervera, Á., Molés, F., Peris, B., \& Verdú, G. (2015). Commercial refrigeration-an overview of current status. International journal of refrigeration, 57, 186-196.

[3] Park, C., Lee, H., Hwang, Y., \& Radermacher, R. (2015). Recent advances in vapor compression cycle technologies. International Journal of Refrigeration, 60, 118-134.

[4] Llopis, R., Nebot-Andres, L., Sánchez, D., Catalán-Gil, J., \& Cabello, R. (2018). Subcooling methods for CO2 refrigeration cycles: A review. International Journal of Refrigeration, 93, 85-107.

[5] Arora, A., \& Kaushik, S. C. (2008). Theoretical analysis of a vapour compression refrigeration system with R502, R404A and R507A. International journal of refrigeration, 31(6), 998-1005.

[6] Meng, X., Qiu, G., Wu, J., \& Abdulagatov, I. M. (2013). Viscosity measurements for 2, 3, 3, 3-tetrafluoroprop-1-ene (R1234yf) and trans-1, 3, 3, 3-tetrafluoropropene (R1234ze (E)). The Journal of Chemical Thermodynamics, 63, 24-30.

[7] Qiu, G., Meng, X., \& Wu, J. (2013). Density measurements for 2, 3, 3, 3tetrafluoroprop-1-ene (R1234yf) and trans-1, 3, 3, 3-tetrafluoropropene (R1234ze (E)). The Journal of Chemical Thermodynamics, 60, 150-158.

[8] Agrawal Shyam (2019) Thermodynamic and Exergy analysis of thermal systems, Ph.D. thesis, Delhi, Technological university, Delhi (India).

Cite this article as: R.S. Mishra, Shyam Agarwal, Thermodynamic analysis of vapor compression refrigeration cycle using expander as an expansion device, International Journal of Research in Engineering and Innovation Vol-3, Issue-5 (2019), 326-329. 